\title{
MODEL OF FORMING ISOTROPIC AND ANISOTROPIC GRAPHITE UNDER HIGH TEMPERATURES AND FLUENCES NEUTRON IRRADIATION
}

\author{
Mykola P. Odeychuk ${ }^{1}$, (DVictor I. Tkachenko ${ }^{1,2}$, Deonid A. Bulavin ${ }^{3}$, \\ (D) Boris V. Borts ${ }^{1}$, DStella I. Skoromnaya ${ }^{1}$ \\ ${ }^{I}$ National Science Center Kharkiv Institute of Physics and Technology \\ 1, Academichna Str., 61108 Kharkiv, Ukraine \\ ${ }^{2}$ V.N. Karazin Kharkiv National University \\ 4, Svobody Sq., 61022 Kharkiv, Ukraine \\ ${ }^{3}$ Taras Shevchenko National University of Kyiv \\ 64/13, Volodymyrska Street, 01601 Kyiv, Ukraine \\ *E-mail: odeychuk@kipt.kharkov.ua
}

Received August 20, 2019; revised October 8, 2019; accepted November 18, 2019

\begin{abstract}
A model is proposed for describing the shape change of isotropic and anisotropic graphite under the influence of high temperatures and high neutron radiation fluences. The model is based on a new approach, which uses the following provisions: description of the near-pore neighborhood in graphite as a solid solution using the theory of phase transformations of the first kind; consideration of a new phase as a spheroidal pore of small eccentricity, flattened along the direction of greatest stress; taking into account the clustering of carbon atoms at fluences of more than $2 \times 10^{26} n / \mathrm{m}^{2}$. The graphite non-isotropy is characterized by different pore sizes, different diffusion coefficients, the lengths of the paths of graphite atoms along and across volume of the sample, which in turn depend on the temperature of the sample. It is proposed that the initial element on the basis of which a new phase will be formed is the spheroidal pore of small eccentricity, flattened along the direction of the highest tension. A kinetic equation that describes the diffusion of pores under the influence of high temperatures and intense neutron fluxes is obtained. Initially, the pores are in a field of predetermined stresses oriented along and across the sample. The contribution of diffusion processes is due to the term proportional to the pore distribution function in the sample, and the effect of the neutron flux is described by an additional term in the kinetic equation. The obtained kinetic equation for anisotropic graphite can be transformed for isotropic graphite. For isotropic and anisotropic graphite, model solutions have been obtained that characterize the change in its volume with time under the influence of a neutron flux and high temperature. It is shown that the magnitude of the change in the relative volume of reactor graphite for isotropic graphite exceeds a similar value for anisotropic graphite. Theoretical confirmation of the laws governing the swelling of anisotropic graphites under the influence of large neutron fluences and in the high-temperature field, previously obtained by other authors, is obtained: longitudinal compression of anisotropic graphite samples corresponds to a change in the linear dimensions of isotropic graphites; the transverse compression of anisotropic graphite samples is less than the change in the longitudinal linear dimensions of isotropic graphites.
\end{abstract}

KEY WORDS: theory, graphite, forming, neutron, fluence, high temperature

The radiation dimensional stability of graphite is its most important characteristic and it largely determines its performance as a material and construction as a whole [1-7]. The rate and nature of changes in the size of graphite products depend on irradiation temperature and are changing in the process of the set of neutron fluence at a fixed temperature. In the general case, the change in the dimensions of carbon materials under the influence of neutron irradiation is in a complicated dependence on the irradiation conditions: from the magnitude of the integral flow and temperature. As a rule, at the initial stage of irradiation the accelerated shrinkage of irradiated graphite is observed. With the growth of the neutron fluence the shrinkage rate is slowing, and then reverses the sign - shrinkage is replaced by secondary swelling.

The rate of secondary swelling of graphite is higher than the rate of shrinkage, and this is accompanied by a change in its physical properties. In graphite develops microcracks, which become larger and merge and form macrocracks [4].

The strength of the material decreases, which should limit the service life of the reactor, and, consequently, the entire masonry of the reactor.

The increasing of temperature reduces the dose corresponding to the transition from shrinkage to secondary swelling and increases the speed of the latter.

It is known that metals irradiated for a long time pass into a state of saturation with point defects. This state is unstable to the nucleation and formation of volumetric accumulations of vacancies in the form of vacancy pores. As a result of the formation of such cavities in the metal, an increase in its initial volume is observed, thus its swelling occurs. First vacancy swelling of metal about $10 \mathrm{~nm}$ in size associated with the cell was discovered experimentally in 1967. Moreover, as it turned out, swelling, such as steel, it may be $6 \%$ or more of the initial volume

The most undesirable consequences of swelling include deformation, bends and an increase in the size of various structures that can lead to self-welding of individual parts, jamming, as well as to overheating inside the working units. Exposed radiation swelling phenomenon correlates not only for metals, but also for widely used as a neutron absorber reactor graphite. 
In some types of nuclear reactors, graphite components are used inside the nuclear reactor as structural elements. Irradiation of neutron fluxes and high temperature carried to deformation (creep) graphite to disruption of its structural integrity. Therefore, the experimental and theoretical investigations of graphite forming under the influence of the above factors are important for the safe operation of nuclear reactors. In this direction, active research work is carried out, as a result of which theoretical models [8] are created that give a good correspondence with the experimental data on the graphites forming. However, it should be noted that the experimental database on the graphite forming under the influence of irradiation and high temperatures does not possess completeness and is fragmentary.

The purpose of this work is the development of the theory of graphite forming under the influence of high temperatures and high fluences of neutrons on the basis of the theory of phase transformations of the first kind, in which the near-porous neighborhood of graphite is considered as a solid solution $[9,10]$, or similar to a liquid medium [11].

\section{FORMULATION OF THE PROBLEM \\ Graphite forming under the influence of neutron fluxes of large fluences in a high-temperature field. Initial information about the graphite forming}

The effect of neutron fluxes of large fluences and high temperatures on nuclear graphite, to some extent, is similar to the formation of pores in solid solutions under the influence of certain external factors. In the latter case, phase transformations of the first kind take place, accompanied by the formation of pores in a solid $[9,10]$ or bubbles in a liquid [11].

The formation of pores in reactor graphite taking into account [9-11] can be described as follows.

In a simplified embodiment the reactor graphite is a mixture of petroleum coke and coal tar. Blocks are pressed from this mixture, usually about $500 \mathrm{~mm}$ in diameter and about $2000 \mathrm{~mm}$ in length, and then these blocks are processed at a high (up to $3000{ }^{\circ} \mathrm{C}$ ) temperature. In the process of heat treatment, pores are formed in graphite, the amount of which (porosity) depends from the technology of production.

As practice shows, graphites under the influence of load and irradiation, as well as metals are subject to pore formation processes [2,12], as a result of which their dimensional changes take place.

However, these processes must occur in different scenarios due to the fact that for different graphite marks may vary not only the initial porosity, density and strength characteristics, but also internal stresses, which are caused by the method of graphite making. So, for example, there are isotropic graphites, in the manufacture of which isostatic pressing is used. For anisotropic graphites, which are produced with using traditional pressing methods with uniaxial compression, which determines the difference in properties of these graphites along the axes a and $\mathbf{c}$.

The pressure in the pore is created by an inert gas, in which medium the production of reactor graphite takes place and at the initial instant of time always exceeds the pressure in the crystalline structure of graphite. During irradiation and temperature loading, graphite loses its elastic properties and passes into a state where the pressure in the pore tends to pressure in the crystal, slightly exceeding it.

The finished product is composed of compacted graphite fine grain size of about $500 \AA$ [5] with different orientation of the graphite planes. The porosity of reactor graphite is usually about $26 \%$, and in modern grades of reactor graphite - $(9-10) \%$.

The interaction of neutrons with the carbon atoms of the grain is accompanied by the formation of vacancies and the removal of atoms into the interstitial space. Moreover, along with the modification of the initially existing micropores, the formation of new pores is also observed in reactor graphite, i.e. the formation of a new phase.

In virtual space, the formation of a new phase can be viewed as the result of mutual transitions of carbon atoms from one phase (atoms at lattice sites or in internodes) to another phase (the pores formed by the accumulation of vacancies). It can be assumed that the crystal lattice of graphite in the immediate vicinity of the pore is strongly saturated with point defects (carbon atoms located in internodes).

Conditionally, we will consider a pore as such, which is not located in the crystal lattice, but in an amorphous, liquid-like medium located near the pore surface and consisting from irregularly arranged carbon atoms.

The phenomenon of amorphization of the reactor graphite is studied for a long time [13-16]. Graphite can be amorphized under the influence of high-energy ions, neutrons or electrons. Judging by the diffraction pattern of a transmission electron microscope (TEM), observed along the axis c, amorphization occurs when samples are irradiated to a dose of about 1 atomic displacement (sleep) at room temperature [13].

A schematic representation of the pore surrounded by an amorphous or liquid-like medium inside a graphite crystal is shown in Fig. 1.

With such an examination, the near-pore neighborhood can be considered as a solid solution, and the theory of phase transformations of the first kind can be applied to its description [9-11].

As follows from this theory, the equations describing the phase transformations contain coefficients that are expressed in terms of the coefficients: viscosity $\eta$, diffusion $D$, surface tension $\sigma$, as well as the mean free path of a point defect (carbon atom) in the crystal lattice $l$. These coefficients have a certain view [9-11] and can be used to construct a fundamental system of equations describing the time variation of the distribution pores function in a space of dimensions, which include the coordinates and velocities of the centers of spherical pores, as well as their size and the quantity of vacancies in them. 


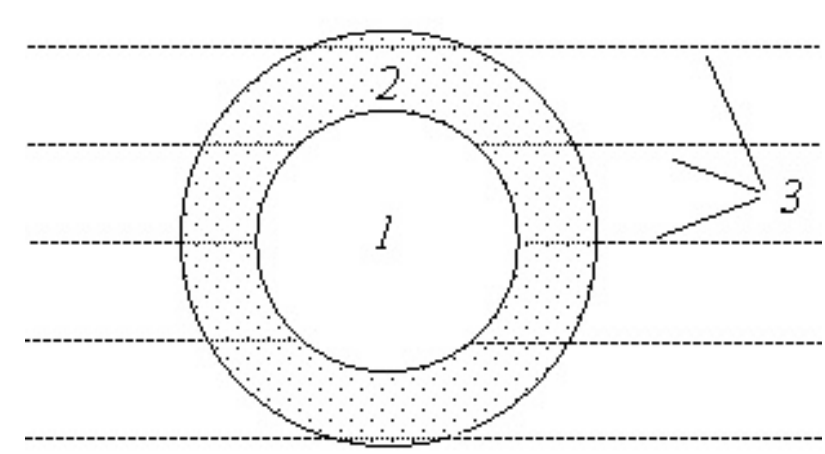

Fig.1. Location of the vacancy pore in a graphite crystal 1 - vacancy pore, 2 - liquid-like medium near the pore, 3 hexagonal planes of a graphite crystal.

For description of the phase transformations in reactor graphite, we will assume that the processes of pore formation during heat treatment of graphite at high temperatures and under the influence of neutron fluxes are similar. In the first case, the source of energy for the formation of a new phase is high temperature, in the second - a moderate temperature and neutron flux.

In isotropic graphite, the displacement of carbon atoms is isotropic due to the isotropy of internal stresses.

In anisotropic graphite, the knocked out carbon atoms will move in an inhomogeneous force field, which is characterized by various internal longitudinal $\sigma_{P}$ and transverse $\sigma_{T}$ mechanical stresses of the sample. Ultimately, the carbon atoms will preferably be displaced to the region of equal internal pressure from the medium, i.e., to the axis of the axisymmetric internal field of internal tension of the non-isotropic sample. In this connection, the formed pores will reflect the structure of internal stresses in the sample, and will apparently have the form of an ellipsoid of revolution. Such ellipsoidal form of pores is established as a result of computer analysis of plane optical images of reactor graphite samples [17]. Here, optical images obtained as a result of structural studies quantitatively revealed changes in the structure of pores and their cross-sectional area and the values of the eccentricity of the ellipses (0.908, 0.931, 0.929 and 0.922 for IG-110, PGX, NBG-18 and PCEA graphite samples respectively) and their preferential orientation was identified.

\section{Theoretical model of graphite forming under the influence of neutron fluxes of large fluences in a high-temperature field}

On the basis of the foregoing, we obtain a kinetic equation for the pore distribution function having the form of an ellipsoid of revolution in anisotropic graphite under the influence of large neutron fluences and at high temperatures.

We assume that the distribution of pores in a viscous medium at a given time $t$ is determined by the distribution function $f\left(\vec{r}_{T}(t), \vec{r}_{P}(t), \overrightarrow{\mathrm{v}}_{T}(t), \overrightarrow{\mathrm{v}}_{P}(t), V_{T}(t), V_{P}(t), N_{T}(t), N_{P}(t), t\right)$, in which the variables are as follows: $V_{T}(t)=\frac{4 \pi}{3} R_{T}^{2} R_{P}-$ pore volume at constant radius along the anisotropy direction $R_{P}$ with coordinate $\vec{r}_{T}(t)$ and speed $\overrightarrow{\mathrm{v}}_{T}(t)$ of its center; $N_{T}(t)$ - the number of vacancies in this pore (the number of carbon atoms, retired from the volume $V_{T}(t)$ ); $V_{P}(t)=\frac{4 \pi}{3} R_{T}^{2} R_{P}$ - pore volume, but at a constant transverse it radius $R_{T}$ with coordinate $\vec{r}_{P}(t)$ and speed $\overrightarrow{\mathrm{v}}_{P}(t)$ of its center; $N_{P}(t)$ - number of vacancies in this pore.

When deriving an equation describing the dynamics of the pore distribution function in time $t$ and in the space of variables $\left\{\vec{r}_{\beta}(t), \overrightarrow{\mathrm{v}}_{\beta}(t), V_{\beta}(t), N_{\beta}(t)\right\}$, where the index $\beta$ takes values $\beta=T, P$, it is convenient to introduce a dimensionless number $N_{\beta 1}(t)=V_{\beta}(t) / V_{0}$, where $V_{0}$ - change in pore volume over time $\delta t$, and we assume $\delta t$ so small, that when the volume changes on $V_{0}$ the number of vacancies changes on one. Over the same period of time $\delta t$ coordinate of the center of the pore $\vec{r}_{\beta}(t)$ is displaced on a small amount $\delta \vec{r}_{0}$ with the module $3 \cdot V_{0}^{1 / 3} / 4 \pi$ and the speed will change on a small amount $\delta \overrightarrow{\mathrm{v}}_{\beta}(t)=\delta \vec{r}_{0} / \delta t$ with the module $3 \cdot V_{0}^{1 / 3} /(4 \pi \cdot \delta t)$.

The introduction of a number $N_{\beta 1}(t)$ for the pore distribution function simplifies calculations because the similarity transformation is performed:

$$
\begin{aligned}
& f\left(\vec{r}_{T}(t), \vec{r}_{P}(t), \overrightarrow{\mathrm{v}}_{T}(t), \overrightarrow{\mathrm{v}}_{P}(t), V_{T}(t), V_{P}(t), N_{T}(t), N_{P}(t), t\right) d V_{T} d V_{P}= \\
& =\bar{f}\left(\vec{r}_{T}(t), \vec{r}_{P}(t), \overrightarrow{\mathrm{v}}_{T}(t), \overrightarrow{\mathrm{v}}_{P}(t), N_{1 T}(t), N_{1 P}(t), N_{T}(t), N_{P}(t), t\right) d N_{1 T} d N_{1 P}
\end{aligned}
$$

Where

$$
\begin{aligned}
& V_{0}^{2} \cdot f\left(\vec{r}_{T}(t), \vec{r}_{P}(t), \overrightarrow{\mathrm{v}}_{T}(t), \overrightarrow{\mathrm{v}}_{P}(t), V_{T}(t), V_{P}(t), N_{T}(t), N_{P}(t), t\right)= \\
& =\bar{f}\left(\vec{r}_{T}(t), \vec{r}_{P}(t), \overrightarrow{\mathrm{v}}_{T}(t), \overrightarrow{\mathrm{v}}_{P}(t), N_{1 T}(t), N_{1 P}(t), N_{T}(t), N_{P}(t), t\right)
\end{aligned}
$$

In view of the foregoing, the time variation of the distribution function $\bar{f}\left(\vec{r}_{T}(t), \vec{r}_{P}(t), \overrightarrow{\mathrm{v}}_{T}(t), \overrightarrow{\mathrm{v}}_{P}(t), N_{1 T}(t), N_{1 P}(t), N_{T}(t), N_{P}(t), t\right)$, which we will write in abbreviated form in the form 
$\bar{f}\left(\vec{r}_{\beta}, \vec{v}_{\beta}, N_{1 \beta}, N_{\beta}, t\right)$, is described by the equation:

$$
\frac{d \bar{f}}{d t}=-\left(I_{N_{T}}-I_{N_{T}-1}\right)-\left(I_{N_{T 1}}-I_{N_{T 1}-1}\right)-\left(I_{N_{P}}-I_{N_{P}-1}\right)-\left(I_{N_{P 1}}-I_{N_{P 1}-1}\right)=-\frac{\partial I_{N_{T}}}{\partial N_{T}}-\frac{\partial I_{N_{11}}}{\partial N_{T 1}}-\frac{\partial I_{N_{P}}}{\partial N_{P}}-\frac{\partial I_{N_{P 1}}}{\partial N_{P 1}}+\Phi(t),
$$

where: $I_{N_{\beta}}$ - flow in space $N_{\beta} ; I_{N_{\beta 1}}$ - flow in space $N_{1 \beta}$;

$I_{N_{\beta}}=v_{N_{\beta}, N_{\beta}+1} \bar{f}\left(\vec{r}_{\beta}, \overrightarrow{\mathrm{v}}_{\beta}, N_{1 \beta}, N_{\beta}, t\right)-v_{N_{\beta}+1, N_{\beta}} \bar{f}\left(\vec{r}_{\beta}, \overrightarrow{\mathrm{v}}_{\beta}, N_{1 \beta}, N_{\beta}+1, t\right)$;

$I_{N_{1 \beta}}=v_{N_{1 \beta}, N_{1}+1} \bar{f}\left(\vec{r}_{\beta}, \overrightarrow{\mathrm{v}}_{\beta}, N_{1 \beta}, N_{\beta}, t\right)-v_{N_{1 \beta}+1, N_{1 \beta}} \bar{f}\left(\vec{r}_{\beta}, \overrightarrow{\mathrm{v}}_{\beta}, N_{1 \beta}+1, N_{\beta}, t\right) ; v_{K, K+1}$ - frequency of transition from state $K$ to state $K+1$, where $K=\left\{N_{\beta}, N_{1 \beta}\right\} ; v_{K+1, K}$ - frequency of the reverse transition from state $K+1$ to state $K ; \Phi(t)>0$ monotonic increasing function, describes the influx of neutrons into the volume of a graphite sample. The monotonous growth with time of the function $\Phi(t)$ is explained by the fact that the fast neutron in graphite slows from the mean fission energy to the thermal energy, after experiencing about 114 collisions [5]. It should be noted that the last term in equation (1) characterizes the amorphous action of the neutron flux, i.e. an action aimed at creating point defects in the crystal, which means an increase in the number of pores or their dimensions.

We simplify the record of the subsequent calculations, introducing the abbreviated notation for the distribution function $\bar{f} \rightarrow f$, and come back again to the designation of the pore volume $N_{1 \beta} \rightarrow \tilde{V}_{\beta}$, where the sign "tilde" in subsequent calculations is omitted.

Using the results obtained for isotropic graphite, we can formally generalize them to anisotropic graphite. Allowance for anisotropy leads to an increase in the arguments of the pore distribution function in graphite. The generalization gives the following form of the initial equations:

$$
\frac{d f}{d t}=\sum_{\beta}\left(-\frac{\partial I_{N_{\beta}}}{\partial N_{\beta}}-\frac{\partial I_{N_{1} \beta}}{\partial V_{\beta}}\right)+\Phi(t)
$$

where:

$I_{N_{\beta}}=\frac{d N_{\beta}}{d t} \cdot f\left(\vec{r}_{\beta}, \overrightarrow{\mathrm{v}}_{\beta}, V_{\beta}+1, N_{\beta}, t\right)-D_{N_{\beta}} \cdot \frac{\partial f\left(\vec{r}_{\beta}, \overrightarrow{\mathrm{v}}_{\beta}, V_{\beta}+1, N_{\beta}, t\right)}{\partial N_{\beta}} ; I_{V_{\beta}}=\frac{d V_{\beta}}{d t} \cdot f\left(\vec{r}_{\beta}, \vec{v}_{\beta}, V_{\beta}+1, N_{\beta}, t\right)-D_{V_{\beta}} \cdot \frac{\partial f\left(\vec{r}_{\beta}, \overrightarrow{\mathrm{v}}_{\beta}, V_{\beta}+1, N_{\beta}, t\right)}{\partial V_{\beta}} ;$

$\frac{d N_{\beta}}{d t}=-D_{N_{\beta}} \cdot \frac{1}{T} \cdot \frac{\delta F\left(V_{\beta}, N_{\beta}\right)}{\delta N_{\beta}}, \quad D_{N_{\beta}}=v_{N_{\beta}, N_{\beta}+1}=4 R_{\beta}^{2} \pi \alpha \frac{D_{\beta}}{2 l_{\beta}} n^{L} ; \frac{\delta F\left(V_{\beta}, N_{\beta}\right)}{\delta N_{\beta}}=T \cdot \ln \frac{p^{V_{\beta}}}{p} ;$

$\frac{d V_{\beta}}{d t}=-D_{V_{\beta}} \cdot \frac{1}{T} \cdot \frac{\delta F\left(V_{\beta}, N_{\beta}\right)}{\delta V_{\beta}}, \quad D_{V_{\beta}}=v_{V_{\beta}, V_{\beta}+1} \cdot V_{0}^{2}=\frac{3 V_{\beta} T}{4 \eta_{\beta}} ; \quad \frac{\delta F\left(V_{\beta}, N_{\beta}\right)}{\delta V_{\beta}}=p^{L_{\beta}}-p^{V_{\beta}}+\frac{2 \sigma\left(R_{\beta}\right)}{R_{\beta}} ;$

$F\left(V_{\beta}, N_{\beta}\right)=\sum_{\beta}\left(V_{\beta}\left(p^{L_{\beta}}-p^{\nu_{\beta}}\right)+N_{\beta}\left(\mu^{\nu_{\beta}}-\mu^{L_{\beta}}\right)+\int_{0}^{v_{\beta}} \frac{2 \sigma\left(R^{\prime}\right)}{R^{\prime}} d V^{\prime}\right) ; F\left(N_{\beta 1}, N_{\beta}\right)$ - the difference between the free energy of the medium pore volume $V_{\beta}$ and the number of vacancies $N_{\beta}$ and the free energy of the medium without pores; $T$ medium temperature; $n^{L}$ - density of atoms in a crystal; $\mu^{V_{\beta}}$ - chemical potential of vacancies in the pore; $\mu^{L_{\beta}}$ chemical potential of a crystal atom; $p$ - saturation pressure by pores; $p^{V_{\beta}}$ - the pressure of vacancies in the pore; $p^{L_{\beta}}$ pressure in the crystal along $(\beta=P)$ or across $(\beta=T)$ the axis; $\sigma(R)$ - the coefficient of surface tension at the boundary of the pore, which in general can depend of the pore radius $R_{\beta}(t) ; \eta_{\beta}$ - dynamic viscosity of a crystal along ( $\beta=P$ ) and across $(\beta=T)$ the axis of the stress field of a crystal; $0 \leq \alpha \leq 1$ - a coefficient that takes into account the additional barrier that can exist for the last jump of the carbon atom from the pore; $D_{\beta}, l_{\beta}$ - the diffusion coefficients of the carbon atoms and the length of the elementary displacement of the vacancy in the crystal along $(\beta=P)$ and across $(\beta=T)$ axes of the stress field in the crystal.

Assuming that the medium is uniform in space and in pores no external mechanical forces other than an external radiation source, the equation (2) is simplified and takes the form:

$$
\frac{\partial f}{\partial t}=-\Gamma_{a}(N, V) \cdot f+\sum_{\beta}\left[\frac{\partial}{\partial N_{\beta}}\left(\frac{1}{2} D_{N_{\beta}} \frac{\partial f}{\partial N_{\beta}}\right)+\frac{\partial}{\partial V_{\beta}}\left(\frac{1}{2} D_{V_{\beta}} \frac{\partial f}{\partial V_{\beta}}\right)\right]+\Phi(t),
$$

where: $\Gamma_{a}(N, V)=\frac{1}{2} \sum_{\beta}\left[\frac{\partial}{\partial N_{\beta}}\left(\frac{d N_{\beta}}{d t}\right)+\frac{\partial}{\partial V_{\beta}}\left(\frac{d V_{\beta}}{d t}\right)\right] \equiv \frac{d}{d t} \ln \left(\prod_{\beta}\left|\frac{d V_{\beta}}{d t}\right|\left|\frac{d N_{\beta}}{d t}\right|^{\operatorname{sign}\left(S_{\beta}\right)}\right), S_{\beta} \equiv \frac{d N_{\beta}}{d t} \frac{d V_{\beta}}{d t}$ 
The writing of the term $\Gamma_{a}(N, V)$ in the form of a total time derivative corresponds to a search for the signs of the quantities $\frac{d N_{\beta}}{d t}$ and $\frac{d V_{\beta}}{d t}$, as well as their derivatives by $N_{\beta}$ and $V_{\beta}$ The coefficient $1 / 2$ in equation (4) is necessary to ensure the passage to the kinetic equation describing the creep of isotropic graphite (when the index $\beta$ corresponds only to the value $P$ ) under the influence of large fluences of neutrons at high temperatures.

Thus, the kinetic equation pore diffusion has divergent form in the crystal pore size in the space with the addition of the right side of a term proportional to pore distribution function.

Equation (3) must be supplemented by an equation describing the conservation of the number of atoms in a unit volume, including vacancies in the pores and carbon atoms dispersed in the crystal:

$$
\begin{aligned}
& n^{L}(0)\left(1-\int_{0}^{\infty} \int_{0}^{\infty} \int_{0}^{\infty} \int_{0}^{\infty}\left(V_{T}+V_{P}\right) f\left(V_{\beta}, N_{\beta}, 0\right) d V_{T} d V_{P} d N_{T} d N_{P}\right)= \\
& =n^{L}(t)\left(1-\int_{0}^{\infty} \int_{0}^{\infty} \int_{0}^{\infty} \int_{0}^{\infty}\left(V_{T}+V_{P}\right) f\left(V_{\beta}, N_{\beta}, t\right) d V_{T} d V_{P} d N_{T} d N_{P}\right)+ \\
& +\int_{0}^{\infty} \int_{0}^{\infty} \int_{0}^{\infty} \int_{0}^{\infty}\left(N_{T}+N_{P}\right) f\left(V_{\beta}, N_{\beta}, t\right) d V_{T} d V_{P} d N_{T} d N_{P}
\end{aligned}
$$

Equations (3) and (4) constitute a system that describes the change in time $f\left(V_{\beta}, N_{\beta}, t\right)$ and $n^{L}(t)$. For a complete description of the time dynamics of these parameters in a medium, the system of equations must be supplemented by initial and boundary conditions.

In order to compare the parameters of the forming of isotropic and anisotropic graphites under the influence of large neutron fluences and in a high-temperature field, we briefly describe the phenomenological theory of the isotropic graphite forming.

\section{QUALITATIVE ANALYSIS OF ISOTROPIC GRAPHITE FORMING UNDER THE INFLUENCE OF HIGH TEMPERATURES AND LARGE NEUTRON FLUENCES}

Analysis of the isotropic graphite forming under the influence of neutron fluences to $2 \times 10^{26} \mathrm{n} / \mathrm{m}^{2}$

Equation (3) describes the time variation of the pore distribution function in an isotropic graphite crystal in the case when the pore is spherically symmetric $R_{P}=R_{T}$, and the index $\beta$ takes only the value $T$.

This equation can be analyzed in the simplest case, when the pore distribution function depends only on the time $f=n(t)$, and does not depend on the variables $V$ and $N$. Then we can assume that all pores have the same volume $V_{u}$ and contain an equal number of vacancies $N_{u}$. In this case, the total volume occupied by the pores is:

$$
V_{\Sigma}(t)=\frac{1}{N_{u}} \int_{0}^{N_{u}} \int_{0}^{V_{u}} f(t) d V d N=n(t) V_{u} .
$$

It follows from expression (5) that the change in the volume of graphite in the case under consideration is proportional to the distribution function of the pores in the space of dimensions. Moreover, the distribution function is normalized in such a way that at the initial time it is equal to the total number of pores in a unit volume of graphite: $n_{i}(0)=N_{\Sigma}$. For describing of the change in pore volume per unit volume of graphite, it is necessary to find a solution of equation (3), which, taking into account the above assumptions about the form of the distribution function, takes the form:

$$
\frac{d n_{i}(t)}{d t}=-\Gamma(N(t), V(t)) \cdot n_{i}(t)+\Phi(t),
$$

where the index $i$ denotes isotropic graphite.

Equation (6) is a linear differential equation, whose solution has a simple form:

$$
n_{i}(t)=\exp (-F(t))\left(n_{i}(0)+\int_{0}^{t} \Phi(x) \cdot \exp (F(x)) d x\right),
$$

where $F(t)=\int_{0}^{t} \Gamma(N(x), V(x)) d x$.

For the analysis of solutions (7) introduces the simplifying assumptions:

- we assume that $\Gamma(N(t), V(t))$.is a positive constant, i.e. $\Gamma(N(t), V(t))=C_{1}=$ const $>0$;

- we assume that the contribution of the neutron term on the right-hand side of (7) is described by a linear function of time: $\Phi(t)=\Phi_{0} \cdot t$.

In this case, the solution of (7) takes the form: 


$$
n_{i}(\tau)=n_{i}(0)\left(1+X_{i}\right)\left(\exp (-\tau)-1+\frac{\tau X_{i}+1}{1+X_{i}}\right)
$$

where $\tau=C_{1} \cdot t$ - dimensionless time, $X_{i}=\Phi_{0}\left(C_{1}^{2} n_{i}(0)\right)^{-1}$ - parameter describing the neutron flux and the properties of isotropic graphite.

When calculating the total volume occupied by the pores, it was introduced by the assumption of the constancy of the pore size. Therefore, the total volume of pores will change only as a result of a change in their number.

If we proceed from this model representation, we can determine from (8) the change in the relative pore volume of isotropic reactor graphite in a result of exposure to high temperature and intense neutron flux:

$$
\left.\frac{\Delta V_{\Sigma}(\tau)}{V_{\Sigma}(0)}\right|_{i}=\frac{\left(n_{i}(\tau)-n_{i}(0)\right)}{n_{i}(0)}=\left(1+X_{i}\right)\left(\exp (-\tau)-1+\tau \frac{X_{i}}{1+X_{i}}\right)
$$

From the expression (9) follows that at the initial time the change of the pore volume is zero. The influence of the neutron flux and temperature leads to a change in the total pore volume. In Fig. 2 shows a qualitative curve described by expression (9), and displaying the change in the relative volume of pores in the graphite with the time $\tau$ when the parameter $X_{i}=7$. As follows from Fig. 2, graphite under irradiation first shrinks and then swells. This behavior of graphite under irradiation corresponds with experimental results.

From (9) we can determine the time to reach the maximum compression of the sample $\tau_{\max }=\ln \left(\frac{1+X_{i}}{X_{i}}\right)$ and the maximum relative compression of its volume:

$$
\left(\left.\frac{\Delta V_{\Sigma}(\tau)}{V_{\Sigma}(0)}\right|_{i}\right)_{\max }=X_{i} \ln \left(\frac{1+X_{i}}{X_{i}}\right)-1 .
$$

Analyzing the behavior of the curve in Fig. 2, it can be concluded that the change in the relative volume of pores of reactor graphite is due to the flow of two mutually exclusive processes. The first process is due to the decrease in time (exponentially) of the number of pores as a result of diffusion of point defects (thermal diffusion of graphite atoms in the graphite crystal lattice). The second process is characterized by a time-linear increase in the number of pores and is associated with the amorphization of graphite under the influence of fast neutron flux.

It should be noted that the dimensionless time can be expressed through the fluence of fast neutrons, since its value is proportional to the integral dose of irradiation of graphite by neutrons.

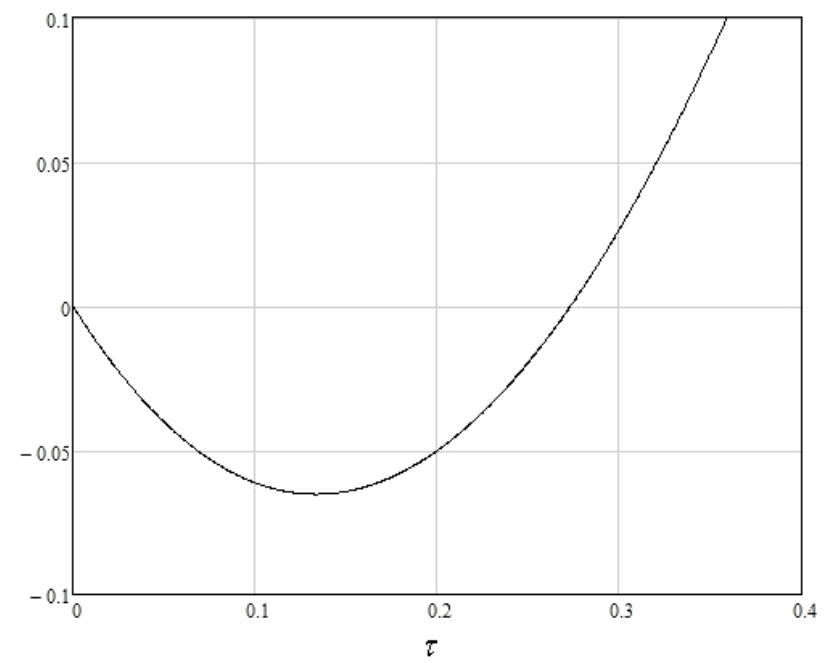

Fig.2. A qualitative curve for the change in the relative volume of pores in isotropic graphite with a dimensionless time $\tau$.

Analysis of the isotropic graphite forming under the influence of neutron fluences is more $2 \times 10^{26} \mathrm{n} / \mathrm{m}^{2}$

With increasing neutron fluence to a value more $2 \times 10^{26} \mathrm{n} / \mathrm{m}^{2}$ it's necessary, in our opinion, take into account the growing number of formation of lattice defects (vacancies) of reactor graphite. Displaced carbon atoms are clustered in small groups of 5-10 atoms [3]. At this stage, due to neutron scattering on such clusters, the effect of increasing (accumulating) neutron fluence should be observed. For process modeling of increasing the neutron fluence, we shall assume in the right-hand side of equation (3) that the function $\Phi(t)$ in the form:

$$
\Phi(t)=\Phi_{0} t+\Phi_{1} t^{2}
$$


The solution of equation (7) in this case takes the form:

$$
n_{i}^{+}(\tau)=n_{i}(0)\left(1+X_{i}\right)\left((\exp (-\tau)-1)\left(1-\frac{2 d \cdot X_{i}}{1+X_{i}}\right)+\frac{\tau X_{i}+1}{1+X_{i}}+\frac{d \cdot X_{i}}{1+X_{i}} \tau(\tau-2)\right),
$$

where $d=\frac{\Phi_{1}}{\Phi_{0} C_{1}}$ - constant, which is depending from the property of clustering of reactor graphite.

In order to determine the applicability of expression (12) for describing the change in the relative elongation of reactor graphite parallel to the direction of its formation, we use experimental data [3]. In Fig. 3 shows the experimental points on which the analytical dependence (12) is imposed for the values $X_{i}=1.3, d \cdot X_{i}=177.87$. The dimensionless parameter $\tau$ is related with the neutron fluence by the relation: $\tau=\tau_{0} \cdot 10^{-22} \Phi$, where $\tau_{0}=30.72$.

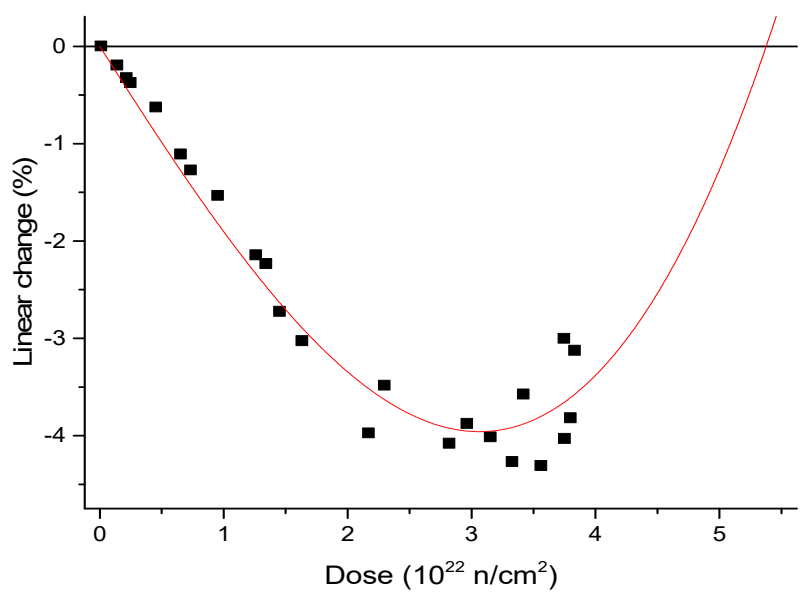

Fig.3. Changing the linear dimensions of the $\mathrm{H} 451$ reactor graphite sample parallel to the direction of its formation at $600{ }^{\circ} \mathrm{C}[3]$.

In Fig. 3 within the limits of permissible experimental errors seen a good quantitative correspondence of the proposed model to the experimental data.

Thus, this analytical representation of the effect of clustering of reactor graphites under the influence of increased levels of neutron fluxes is applicable to the description of the reactor graphite forming under the influence of high temperatures and increased neutron fluxes.

\section{The condition of applicability of the isotropic graphite forming model under the influence} of neutron fluences and high temperatures

Consider the conditions for the applicability of the solution (8). It was obtained under the assumption of the validity of the relation:

$$
\Gamma(N, V)=C_{1}>0
$$

The relation (13) can be detailed using the notation of symbols included in the expression $\Gamma(N, V)$. It can be rewritten in the form of an equation, using expressions $(2,3)$ :

$$
\frac{d}{d t} \ln \left(\left|\frac{d V}{d t} \| \frac{d N}{d t}\right|^{\operatorname{sign}(S)}\right)=C_{1} .
$$

The solution of equation (14) gives the following relationship between the parameters of reactor graphite:

$$
\left|\frac{d V}{d t}\right|\left|\frac{d N}{d t}\right|^{\operatorname{sign}(S)}=C_{4} e^{-C_{1} t} .
$$

From the condition $C_{4}>0$ that are chosen in the solution (15), it follows that the sign of the parameter $S=\frac{d N}{d t} \frac{d V}{d t}$ has a positive value. In this case, finally, taking into account (2), (3), equation (15) takes the following form:

$$
\pi \alpha R^{2} \frac{D}{l} n^{L} \frac{3 V}{2 \eta}\left(p^{L}-p^{V}+\frac{2 \sigma_{P}}{R}\right) \ln \left(\frac{p^{V}}{p^{L}}\right)=C_{4} e^{\tau}
$$


where it is considered the assumption of the validity of the condition of equilibrium on the surface of the pore, $p(R, t) \approx p^{L}$, and also the fact was used, that the surface tension of pores of large dimensions does not depend on the size of the pores, i.e. $\sigma(R)=\sigma_{P}$. The constant $C_{4}$ is determined by the values of all the parameters specified in equation (17) at the initial moment of time $(\tau=0)$.

Equation (16) determines the temporal dynamics of the change in the ratio of pressures inside the pore $p^{V}$ and outside the pore $p^{L}$. From this equation it follows that the effect of high temperature and intense neutron flux indirectly affect the ratio of pressures inside and outside the pore through the coefficients of viscosity $\eta$, diffusion $D$, surface tension $\sigma_{p}$, and also through a point defect free path length $l$ (carbon atoms) in the crystal lattice.

Equation (16) has a solution expressed in terms of the ratio of pressures $p^{V} / p^{L}$ :

$$
\tau=-\ln \left(C_{4}^{\prime}\right)+\ln \left(\left(1-\frac{p^{V}}{p^{L}}+\frac{2 \sigma_{P}}{R p^{L}}\right) \ln \left(\frac{p^{V}}{p^{L}}\right)\right),
$$

where $C_{4}^{\prime}=\frac{C_{4}}{\pi \alpha R^{2} p^{L} \frac{D}{l} n^{L} \frac{3 V}{2 \eta}}$.

It follows from equality (17) that for all pores of the same volume $V_{\mathrm{u}}$ and an equal number of vacancies in them $N_{u}$, the ratio of pressures $p^{V} / p^{L}$ should depend on time. This means that the value $p^{L}$ is constant, and $p^{V}$ - function of time.

Thus, expression (17) determines the dependence of the relative pressure in the pore $p^{V} / p^{L}$ on time.

In Fig.4 shows graphs of the dependence of the dimensionless time $\tau$ from the ratio of pressures $p^{V} / p^{L}$ for different values of the constants: $\frac{2 \sigma_{P}}{R p^{L}}$ and $C_{4}^{\prime}$.

Starting from the family of curves in Fig. 4, we can conclude that these curves for the same values of the constant $C_{4}^{\prime}$ and different values $\frac{2 \sigma_{P}}{R p^{L}}$ do not intersect. However, the appropriate choice of these constants can be ensured, at least, by the intersection of two of these curves. Such an intersection can lead to a change in the time dynamics of the relative pressure in the pore: with increasing time, the decrease in the relative pressure in the pore can be replaced by its growth. For example, the intersection of curves 1 and 5, shown in Fig. 5, may lead to the following change in the pressure in the pore: point a in Fig. 5 is to the left of the maximum of curve 5. Therefore, with increasing time the pressure in the pore must decrease in accordance with the direction of travel along the arrow from point a to point $b$. When reaching the point $b$, corresponding to the intersection of curves 1 and 5 , the pressure reduction in the pore is changed to its increase, which corresponds to moving along the curve 5 from point $\mathrm{b}$ to point $\mathrm{c}$.

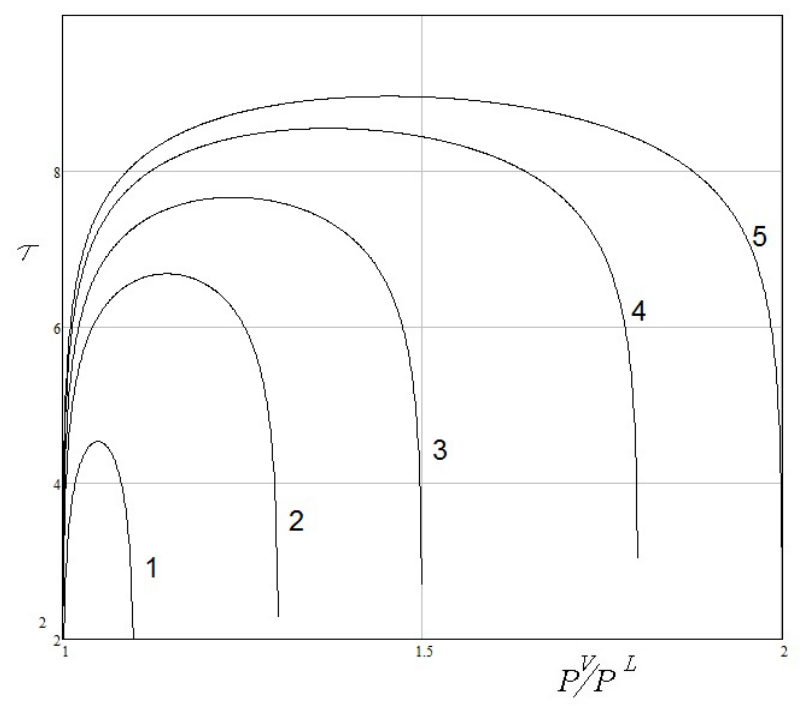

Fig. 4. Curves of the dependence of the dimensionless time $\tau$ from the ratio of pressures $p^{V}\left(p^{L}\right)^{-1}$ at a value $C_{4}^{\prime}=10.55$ :

$$
1-\frac{2 \sigma_{P}}{R p^{L}}=0.1 ; 2-\frac{2 \sigma_{P}}{R p^{L}}=0.3 ; 3-\frac{2 \sigma_{P}}{R p^{L}}=0.5 ; 4-\frac{2 \sigma_{P}}{R p^{L}}=0.8 ; 5-\frac{2 \sigma_{P}}{R p^{L}}=1.0
$$


Thus, the presented numerical estimates demonstrate the validity of the condition (13). This condition can be fulfilled with a corresponding change in the relative pressure in the pore without changing its relative volume. The relative pore volume of isotropic reactor graphite, as noted in (5), will vary due to a change in the total number of pores.

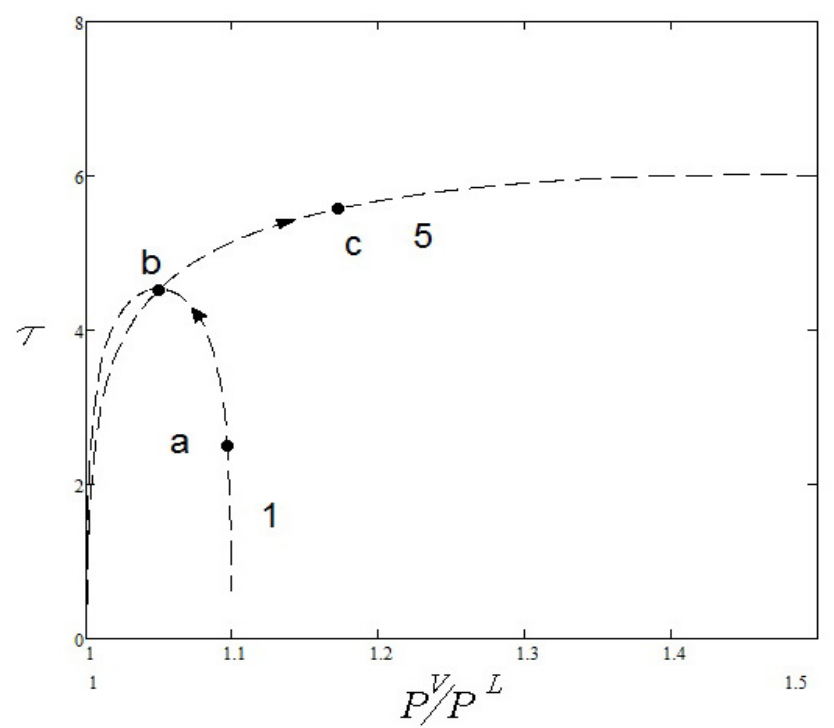

Fig.5. Intersection of curves 1 and 5 at values: $\left.C_{4}^{\prime}\right|_{1}=10.55$ and $\left.C_{4}^{\prime}\right|_{5}=7.6$.

\section{QUALITATIVE ANALYSIS OF ANISOTROPIC GRAPHITE FORMING UNDER THE INFLUENCE OF HIGH TEMPERATURES AND LARGE NEUTRON FLUENCES}

Analysis of the anisotropic graphite forming under the influence of neutron fluences to $2 \times 10^{26} \mathrm{n} / \mathrm{m}^{2}$

For anisotropic graphite equation (3) can be analyzed for homogeneous in the variables $V$ и $N$ of pore distribution function, but depends only on the time $f=n_{a}(t)$. Then we can assume that all the pores have the same volume $V_{\beta u}$ but different shape (compressed or elongated ellipsoid of revolution), and contain an equal number of vacancies $N_{\beta u}$. In this case, the total volume occupied by the pores is:

$$
V_{\Sigma}^{2}(t)=\frac{1}{N_{T u} N_{P u}} \int_{0}^{N_{T_{u}}} \int_{0}^{V_{T_{u}}} \int_{0}^{N_{P_{u}}} \int_{0}^{V_{P_{u}}} f(t) d V_{T} d N_{T} d V_{P} d N_{P}=n_{a}(t) V_{T u} V_{P u} .
$$

It follows from expression (18) that the pore volume in anisotropic graphite is proportional to the pore distribution function in the size space. The distribution function is normalized in such a way that at the initial time it is equal to the total number of pores in a unit volume of graphite: $n_{a}(0)=N_{T \Sigma} N_{P \Sigma}$. For describing of the change in pore volume per unit volume of graphite, it is necessary to find a solution of equation (3), which, taking into account the above assumptions about the form of the distribution function, has the form:

$$
\frac{d n_{a}(t)}{d t}=-\Gamma_{a}(N(t), V(t)) \cdot n_{a}(t)+\Phi(t),
$$

where $N_{P}(t)=N_{T}(t)=N(t), N_{P}(t)=N_{T}(t)=N(t)$ - by definition, all pores are the same in volume and have an equal number of vacancies.

Equation (19) is a linear differential equation whose solution has a simple form:

$$
n_{a}(t)=\exp (-F(t))\left(n_{a}(0)+\int_{0}^{t} \Phi(x) \exp (F(x)) d x\right)
$$

where $F(t)=\int_{0}^{t} \Gamma_{a}(N(x), V(x)) d x$.

As before, for the analysis of solutions (20) we introduce the simplifying assumptions:

- we consider that $\Gamma_{a}(N(t), V(t))$ is a positive constant, i.e. $\Gamma_{a}(N(t), V(t))=C_{1}^{\prime}=$ const $>0$;

- we assume that the contribution of the neutron term on the right-hand side (20) is described by a linear function of time: $\Phi(t)=\Phi_{0} \cdot t$.

In this case, the solution (20) takes the form:

$$
n_{a}(t)=n_{a}(0)\left(1+X_{a}\right)\left(\exp (-\tau)-1+\frac{\tau X_{a}+1}{1+X_{a}}\right)
$$


where $\tau=C_{1}^{\prime} \cdot t$ - dimensionless time, $X_{a}=\Phi_{0}\left(C_{1}^{\prime 2} n_{a}(0)\right)^{-1}$ - parameter which describing the neutron flux and properties of anisotropic graphite.

Under the condition of constancy of the pore size of the anisotropic reactor graphite relative change of their volume due to the high temperature and intense neutron flux can be determined by the following expression:

$$
\left.\frac{\Delta V_{\Sigma}(\tau)}{V_{\Sigma}(0)}\right|_{a} \equiv \frac{V_{\Sigma}(\tau)-V_{\Sigma}(0)}{V_{\Sigma}(0)}=\frac{\sqrt{n_{a}(\tau)}-\sqrt{n_{a}(0)}}{\sqrt{n_{a}(0)}}=\left(1+X_{a}\right) \frac{\left(\exp (-\tau)-1+\tau \frac{X_{a}}{1+X_{a}}\right)}{1+\sqrt{\left(\exp (-\tau)\left(1+X_{a}\right)+\tau X_{a}-X_{a}\right)}} .
$$

From the expression (22) it follows that:

- at the initial time, the change in pore volume is zero;

- the change in the pore volume in the case of anisotropic graphite is less than for an isotropic graphite.

In Fig. 6, curve 2 corresponds to expression (22), and displays the change in the relative pore volume in anisotropic graphite with time $\tau$ at a parameter value $X_{a}=10$. In Fig. 6 for comparison curve for the change in the volume of isotropic graphite is shown (curve 1).

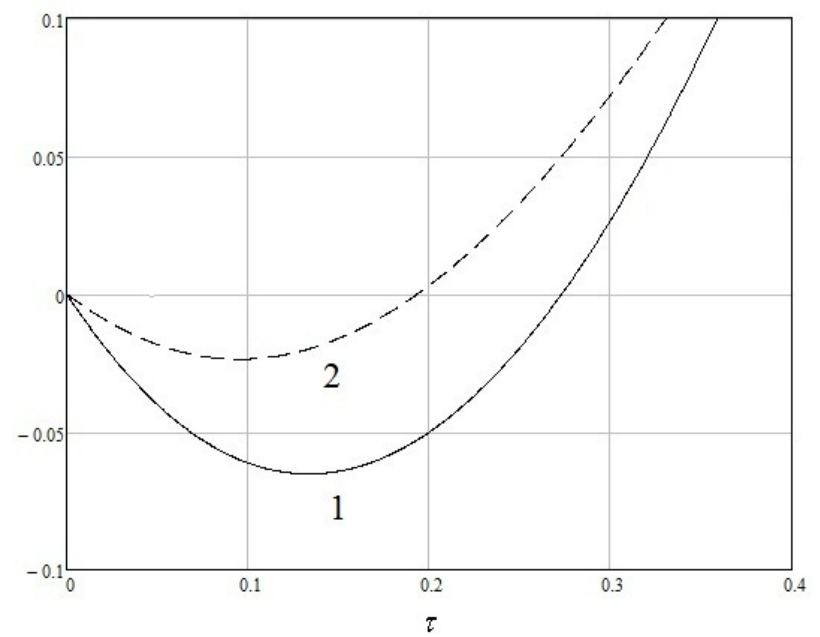

Fig.6. Model curves of the change in the relative volume of pores with dimensionless time $\tau$ in graphites 1 - isotropic graphite; 2 - anisotropic graphite

Analyzing the curves in Fig. 6, we can conclude that the magnitude of the change in the relative volume of reactor isotropic graphite exceeds the analogous value for anisotropic graphite. At the same time, both in one case and in the other, a decrease in the volume of samples is observed first, and then an increase in the volume. Based on the experimental results on the swelling of reactor graphites given in [3], we can formulate the following patterns of swelling of anisotropic graphites under the influence of large fluences of neutrons in a high-temperature field:

- the longitudinal compression of anisotropic graphite samples corresponds to a change in the linear dimensions of isotropic graphites;

- the transverse compression of anisotropic graphite samples is less than the change in the longitudinal linear dimensions of isotropic graphites.

Analysis of the anisotropic graphite forming under the influence of neutron fluences is more $2 \times 10^{26} \mathrm{n} / \mathrm{m}^{2}$.

Taking into account the clusterization of reactor graphite with increased fluences of neutrons of the form (11) gives an expression for changing the number of pores in a unit volume in the direction perpendicular to the molding direction of reactor graphite depending on the dimensionless irradiation time:

$$
n_{a}^{+}(\tau)=n_{a}(0)\left(1+X_{a}\right)\left((\exp (-\tau)-1)\left(1-\frac{2 d_{1} X_{a}}{1+X_{a}}\right)+\frac{\tau X_{a}+1}{1+X_{a}}+\frac{d_{1} X_{a}}{1+X_{a}} \tau(\tau-2)\right),
$$

where $d_{1}=\frac{\Phi_{1}}{\Phi_{0} C_{1}^{\prime}}$ - constant, depending on the property of clustering of reactor graphite.

For determination of the applicability of expression (23), we use the experimental data from work [3]. In Fig.7 shows experimental point on which the analytic dependence (23) is imposed for the values of the parameters $X_{a}=4.0$, $d \cdot X_{a}=30.2$. The dimensionless parameter $\tau$ is related with the neutron fluence $\Phi$ by the relation $\tau=\tau_{0} \cdot 10^{-22} \Phi$, where $\tau_{0}=30.72$. 


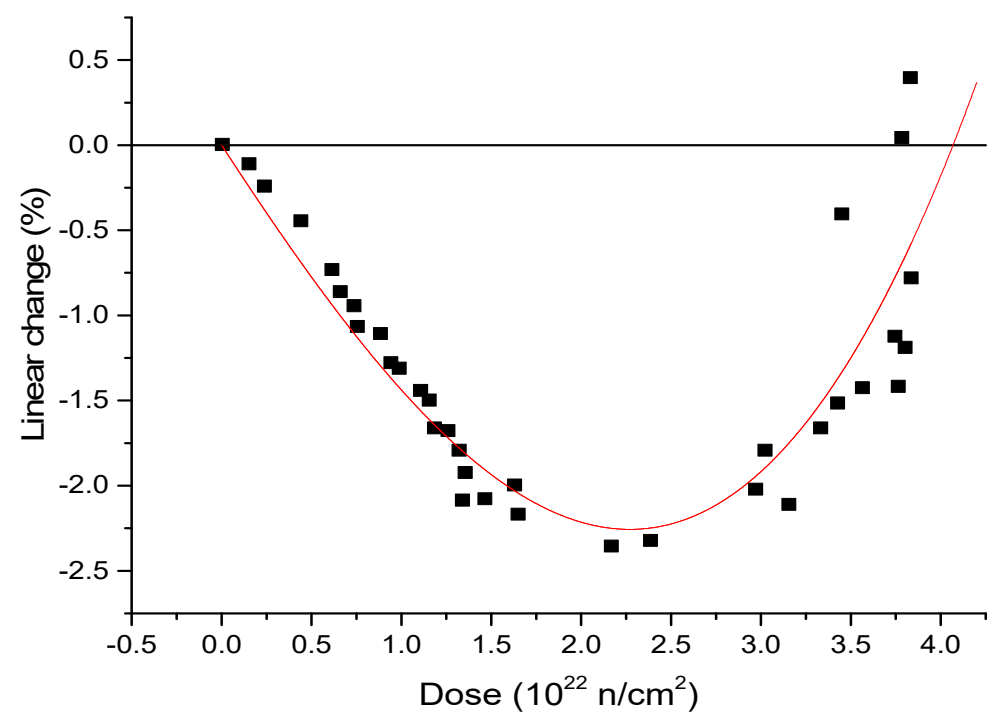

Fig. 7. Changing the linear dimensions of the $\mathrm{H} 451$ reactor graphite sample perpendicularly to the direction of its formation at $600{ }^{\circ} \mathrm{C}[3]$.

Comparison of the experimental data and the theoretical dependence shown in Fig. 7 show their good qualitative and quantitative correspondence.

Thus, the analytical dependence (23), which takes into account the clusterization of reactor graphites under the influence of elevated levels of neutron fluxes and high temperatures, is applicable to the description of the forming of anisotropic reactor graphites.

\section{CONCLUSION}

The model to describe the forming of the isotropic and anisotropic graphite under high temperatures and high fluence neutron radiation was proposed. The non-isotropy of graphite is characterized by different pore sizes, different values of the diffusion coefficients, the mean free paths of the graphite atoms along and the volume of the sample, which in turn depend on the temperature of the sample. It is suggested that the initial element on the basis of which a new phase will be formed is the spheroidal pore of the small eccentricity flattened along the direction of the greatest stress. A kinetic equation is obtained that describes the diffusion of pores under the influence of high temperatures and intense neutron fluxes. Initially, the pores are in a field oriented along and across the sample, given stresses. Contribution of diffusion processes which driven by terms proportional to pore distribution function in a sample, and the effect of the neutron flux is described by an additional term in the kinetic equation. The resulting kinetic equation for anisotropic graphite can be converted for isotropic graphite. Model solutions are obtained for isotropic and anisotropic graphite, which characterize the change in its volume over time under the influence of the neutron flux and high temperature.

It is shown that the change in the relative volume of reactor graphite for isotropic graphite exceeds the analogous value for anisotropic graphite.

Theoretical confirmation of the regularities of the swelling of anisotropic graphites under the influence of large neutron fluences and in the field of high temperatures obtained by other authors was obtained:

- the longitudinal compression of anisotropic graphite samples corresponds to a change in the linear dimensions of isotropic graphites;

- the transverse compression of anisotropic graphite samples is less than the change in the longitudinal linear dimensions of isotropic graphites.

\section{ACKNOWLEDGEMENTS}

This work was supported by the National Academy of Sciences of Ukraine (the project № 0117U004029 "Research and development of radiation technology of accelerated thermal destruction of materials based on carbon with using charged particle accelerators") with according to the Target Comprehensive Program of Scientific Research of the NAS of Ukraine "Scientific Support for the Development of the Nuclear Energy Complex and Advanced Nuclear Technologies".

\section{ORCID IDs}

(D)Mykola P. Odeychuk https://orcid.org/0000-0002-6507-2588, DVictor I. Tkachenkohttp://orcid.org/0000-0002-1108-5842, DLeonid A. Bulavin http://orcid.org/0000-0002-8063-6441, (DBoris V. Borts https://orcid.org/0000-0002-1492-4066, (D) Stella I. Skoromnaya https://orcid.org/0000-0002-9293-5932 


\title{
REFERENCES
}

[1] M.I. Heggie, I. Suarez-Martinez, C. Davidson and G.H. Buckle, Journal of Nuclear Materials. 413, 150-155 (2011), https://doi.org/10.1016/j.jnucmat.2011.04.015

[2] S.V. Panyukov, A.V. Subbotin and M.V. Arzhakov, Journal of Nuclear Materials. 439, 72-83 (2013), https://doi.org/10.1016/j.jnucmat.2013.03.070

[3] Tim Burchell, (2012), e-print in: http://citeseerx.ist.psu.edu/viewdoc/download?doi=10.1.1.565.2836\&rep=rep1\&type=pdf

[4] Irradiation Damage in Graphite due to Fast Neutrons in Fission and Fusion Systems, IAEA-TECDOC-1154, (IAEA, Vienna, 2000), pp. 184, retrieved from: http://www-pub.iaea.org/MTCD/Publications/PDF/te_1154_prn.pdf

[5] Gerd Haag, http://juser.fz-juelich.de/record/49235/files/Juel 4183 Haag.pdf

[6] T.D. Burchell and L.L. Snead, Journal of Nuclear Materials. 371, 18-27 (2007), https://doi.org/10.1016/j.jnucmat.2007.05.021

[7] B.J. Marsden, http://www.iaea.org/inis/collection/NCLCollectionStore/_Public/28/008/28008803.pdf

[8] T.D. Burchell, K.I. Murty and J. Eapen, JOM, 62, 93-99 (2010), https://doi.org/10.1007/s11837-010-0145-0.

[9] I.M. Lifshitz and V.V. Slyozov, The kinetics of precipitation from supersaturated solid solutions, J. Phys. Chem. Solids, 19(1-2), 35 (1961), https://doi.org/10.1016/0022-3697(61)90054-3.

[10] V.V. Slezov, Journal of colloid and interface science, 255, 274-292 (2002), https://doi.org/10.1006/jcis.2002.8610.

[11] B.V. Borts, S.F. Skoromnaya and V.I. Tkachenko, The Journal of Kharkiv National University, physical series "Nuclei, Particles, Fields", 946, 81-89 (2011), http://nuclear.univer.kharkov.ua/lib/946_1(49)_11_p81-89.pdf. (in Russian).

[12] W.J. Gray, Carbon, 11, 383-386 (1973), https://doi.org/10.1016/0008-6223(73) $9007 \overline{8}-\mathrm{X}$.

[13] K. Niwase, Philosophical Magazine Letters, 82, 401-408 (2002), https://doi.org/10.1080/09500830210137416.

[14] K. Niwase, Phys. Rev. B, 52, 15785 (1995), https://doi.org/10.1103/PhysRevB.52.15785.

[15] K. Niwase, K. Nakamura, T. Shikama and T. Tanabe, Journal of Nuclear Materials, 170, 106-108 (1990), https://doi.org/ 10.1016/0022-3115(90)90332-H.

[16] B.A. Gurovich, K.E. Prihod'ko, Problems of atomic science and technology, ser.: Physics of Radiation Effect and Radiation Materials Science, 1(65)-2(66), 156-164 (1997). (in Russian)

[17] B. Rand, P. Bowen, J.F. Knott and B.J. Marsden, in: GTAC Report R39 (2010).

\section{МОДЕЛЬ ФОРМОЗМІНИ ІЗОТРОПНОГО І АНІЗОТРОПНОГО ГРАФІТУ ПІД ДІЕЮ ВИСОКИХ ТЕМПЕРАТУР І ФЛЮЕНСІВ НЕЙТРОННОГО ОПРОМІНЕННЯ}

М.П. Одейчук ${ }^{1}$, В.І. Ткаченко ${ }^{1,2}$, Л.А. Булавін ${ }^{3}$, Б.В. Борц ${ }^{1}$, С.І. Скоромная ${ }^{1}$

${ }^{1}$ Національний науковий центр «Харківський фізико-технічний інститут» вул. Академічна, 1, 61108, Харків, Украӥна

${ }^{2}$ Харківський начіональний університет імені В.Н. Каразіна майдан Свободи, 4, 61022, Харків, Україна

${ }^{3}$ Київський національний університет імені Тараса Шевченка вул. Володимирська, 60, 01033, Київ, Україна

Запропоновано модель для опису формозміни ізотропного і анізотропного графіту під дією високих температур і високих флюенсов нейтронного опромінювання. Модель заснована на новому підході, який використовує такі положення: опис навколопорової околиці в графіті як твердого розчину із застосуванням теорії фазових перетворень першого роду; розгляд нової фази, як сфероїдальної пори малого ексцентриситету, сплюсненої вздовж напрямку найбільшої напруги; облік кластерізації атомів вуглецю при флюенсах більше $2 \times 10^{26} \mathrm{n} / \mathrm{m}^{2}$. Неізотропність графіту характеризується різними розмірами пор, відмінними значеннями коефіцієнтів дифузії, довжинами пробігів, атомів графіту уздовж і поперек об'єму зразка, які в свою чергу залежать від температури зразка. Запропоновано, що початковим елементом, на основі якого буде формуватися нова фаза, є сфероїдальна пора малого ексцентриситету, сплюснута вздовж напрямку найбільшої напруги. Отримано кінетичне рівняння, що описує дифузію пір під впливом високих температур і інтенсивних потоків нейтронів. Спочатку пори знаходяться в полі орієнтованих уздовж і поперек зразка заданих напружень. Внесок дифузійних процесів, обумовлений складовою, пропорційною функції розподілу пор у зразку, а дія нейтронного потоку описується додатковою складовою в кінетичному рівнянні. Отримане кінетичне рівняння для анізотропного графіту може бути перетворено для ізотропного графіту. Для ізотропного і анізотропного графіту отримані модельні рішення, які характеризують зміну його об’єму з часом при впливі потоку нейтронів і високої температури. Показано, що величина зміни відносного об'єму реакторного графіту для ізотропного графіту перевищує аналогічну величину для анізотропного графіту. Отримано теоретичне підтвердження закономірності розпухання анізотропних графітів під впливом великих флюенсів нейтронів і в полі високих температур, раніше отримані іншими авторами: поздовжнє стиснення зразків анізотропних графітів відповідає зміні лінійних розмірів ізотропних графітів; поперечне стиснення зразків анізотропних графітів виявляється менше змінення поздовжніх лінійних розмірів ізотропних графітів.

КЛЮЧОВІ СЛОВА: Теорія, графіт, формозмінення, нейтрон, флюєнс, висока температура

\author{
МОДЕЛЬ ФОРМОИЗМЕНЕНИЯ ИЗОТРОПНОГО И АНИЗОТРОПНОГО ГРАФИТА ПОД ДЕЙСТВИЕМ \\ ВЫСОКИХ ТЕМПЕРАТУР И ФЛЮЕНСОВ НЕЙТРОННОГО ОБЛУЧЕНИЯ \\ М.П. Одейчук ${ }^{1}$, В.И. Ткаченко ${ }^{1,2}$, Л.А. Булавин ${ }^{3}$, Б.В. Борц ${ }^{1}$, С.И. Скоромная ${ }^{1}$ \\ ${ }^{1}$ Национальный научный цеентр «Харьковский физико-технический институт» \\ ул. Академическая, 1, 61108, Харьков, Украина \\ ${ }^{2}$ Харьковский национальныи университет имени В.Н. Каразина \\ пл. Свободыл, 4, 61022, Харьков, Украина \\ ${ }^{3}$ Киевский национальнылй университет имени Тараса Шевченко
} ул. Владимирская, 60, 01033, Киев, Украина

Предложена модель для описания формоизменения изотропного и анизотропного графита под действием высоких температур и высоких флюенсов нейтронного излучения. Модель основана на новом подходе, который использует 
следующие положения: описание околопоровой окрестности в графите как твердого раствора с применением теории фазовых превращений первого рода; рассмотрение новой фазы, как сфероидальной поры малого эксцентриситета, сплюснутой вдоль направления наибольшего напряжения; учет кластеризации атомов углерода при флюенсах более $2 \times 10^{26} \mathrm{n} / \mathrm{m}^{2}$. Неизотропность графита характеризуется разными размерами пор, отличными значениями коэффициентов диффузии, длинами пробегов, атомов графита вдоль и попрек объема образца, которые в свою очередь зависят от температуры образца. Предложено, что первоначальным элементом, на основе которого будет формироваться новая фаза, является сфероидальная пора малого эксцентриситета, сплюснутая вдоль направления наибольшего напряжения. Получено кинетическое уравнение, описывающее диффузию пор под воздействием высоких температур и интенсивных потоков нейтронов. Первоначально поры находятся в поле ориентированных вдоль и поперек образца заданных напряжений. Вклад диффузионных процессов обусловлен слагаемым, пропорциональным функции распределения пор в образце, а воздействие нейтронного потока описывается дополнительным слагаемым в кинетическом уравнении. Полученное кинетическое уравнение для анизотропного графита может быть преобразовано для изотропного графита. Для изотропного и анизотропного графита получены модельные решения, которые характеризуют изменение его объема со временем при воздействии потока нейтронов и высокой температуры. Показано, что величина изменения относительного объема реакторного графита для изотропного графита превышает аналогичную величину для анизотропного графита. Получено теоретическое подтверждение закономерности распухания анизотропных графитов под воздействием больших флюенсов нейтронов и в поле высоких температур, ранее полученные другими авторами: продольное сжатие образцов анизотропных графитов соответствует изменению линейных размеров изотропных графитов; поперечное сжатие образцов анизотропных графитов оказывается меньше изменения продольных линейных размеров изотропных графитов.

КЛЮЧЕВЫЕ СЛОВА: Теория, графит, формоизменение, нейтрон, флюенс, высокая температура 